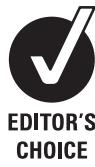

CHOICE

\title{
Parent based language intervention for 2-year-old children with specific expressive language delay: a randomised controlled trial
}

\author{
A Buschmann, ${ }^{1}$ B Jooss, ${ }^{1}$ A Rupp, ${ }^{2}$ F Feldhusen, ${ }^{3}$ J Pietz, ${ }^{1}$ H Philippi ${ }^{1}$
}

\section{See Editorial, p 80}

${ }^{1}$ Department of Paediatric Neurology, Children's Hospital, University of Heidelberg, Heidelberg, Germany; ${ }^{2}$ Section of Biomagnetism, Department of Neurology, University of Heidelberg, Heidelberg, Germany; ${ }^{3}$ Department of Paedaudiology, University of Heidelberg, Heidelberg, Germany

Correspondence to: Anke Buschmann, Department of Paediatric Neurology, Children's Hospital, University of Heidelberg, Im Neuenheimer Feld 150, D-69120 Heidelberg, Germany; anke.buschmann@ med.uni-heidelberg.de

Accepted 30 July 2008 Published Online First 14 August 2008

\section{UNLOCKE}

This paper is freely available online under the BMJ Journals unlocked scheme, see http:// adc.bmj.com/info/unlocked.dtl

\begin{abstract}
Objective: The aim of this randomised controlled trial was to evaluate the effectiveness of a short, highly structured parent based language intervention group programme for 2-year-old children with specific expressive language delay (SELD, without deficits in receptive language).
\end{abstract}

Methods: 61 children with SELD (mean age 24.7 months, SD 0.9) were selected between October 2003 and February 2006 during routine developmental check-ups in general paediatric practices, using a German parent-report screening questionnaire ladapted from the MacArthur Communicative Development Inventories). Standardised instruments were used to assess the language and non-verbal cognitive abilities of these children and of 36 other children with normal language development (reference group; mean age 24.6 months, SD 0.8). 58 children with SELD were sequentially randomly assigned to an intervention group $(n=29)$ or a 12-month waiting group $(n=29)$. In the intervention group, mothers participated in the 3-month Heidelberg Parent-based Language Intervention (HPLI). All children were reassessed 6 and 12 months after pretest. Assessors were blind to allocation and previous results. Results: 47 children were included in the analysis. At the age of 3 years, $75 \%$ of the children in the intervention group showed normal expressive language abilities in contrast to $44 \%$ in the waiting group. Only $8 \%$ of the children in the intervention group versus $26 \%$ in the waiting group met the criteria for specific language impairment (t score $\leqslant 35$ ).

Conclusions: By applying the short, highly structured HPLI in children with SELD, the rate of treatment for language impairment at the age of 3 years can be significantly reduced.

With a prevalence of about 15\% language delay is one of the most frequent developmental problems in 2-year-old children. ${ }^{12}$ Since language delay can be an indicator for several neurodevelopmental problems, it should be taken seriously and further diagnostic investigation is recommended. ${ }^{3}$

There is general agreement regarding the need for intervention for children with persistent deficits in expressive language in the late preschool period and children with deficits in receptive language ${ }^{45}$ But in anticipation that young children with specific expressive language delay (SELD) have a good prognosis and will normalise spontaneously, the "wait and see" strategy is widely recommended, ${ }^{4-6}$ and speech and language therapy is usually not initiated before the age of 4 years. ${ }^{7}$ The main reason for this approach is that language

\section{What is already known on this topic}

- Although a substantial group of children with expressive language delay will not resolve their problem spontaneously, the "wait and see" approach is widely used.

- Parent based language intervention and child directed intervention are effective, but the established programmes are costly and very time consuming.

- Evaluated parent based intervention programmes are not available in German speaking countries.

\section{What this study adds}

- This randomised controlled trial shows that a highly structured and very short parent based language intervention group programme is effective.

- The Heidelberg Parent-based Language Intervention is less expensive and time consuming than other published parent based language interventions.

development is still quite variable in typically developing young children, and it has been shown that many children with SELD normalise, that is, their language skills at the age of 3-5 years are similar to those of their peers. ${ }^{6}$

However, the picture is not entirely clear as other studies have found that at least $50 \%$ of children with SELD do not resolve their problem spontaneously. ${ }^{8-12}$ Studies that started with preschool children with follow-up into school age and adolescence, have found that a substantial proportion of children, in particular those with receptive language impairments, will not outgrow their language difficulties and are therefore at risk for cognitive, literacy, behavioural and psychiatric problems. ${ }^{13-15}$

This unfavourable long term prognosis, combined with parental concerns, child frustration and disturbed parent-child interactions,${ }^{16}$ has led to the development of early intervention models such as individual directed interventions, combined parent-child language groups or parent based group interventions. A limited number of intervention studies have been published. ${ }^{17-22}$ 


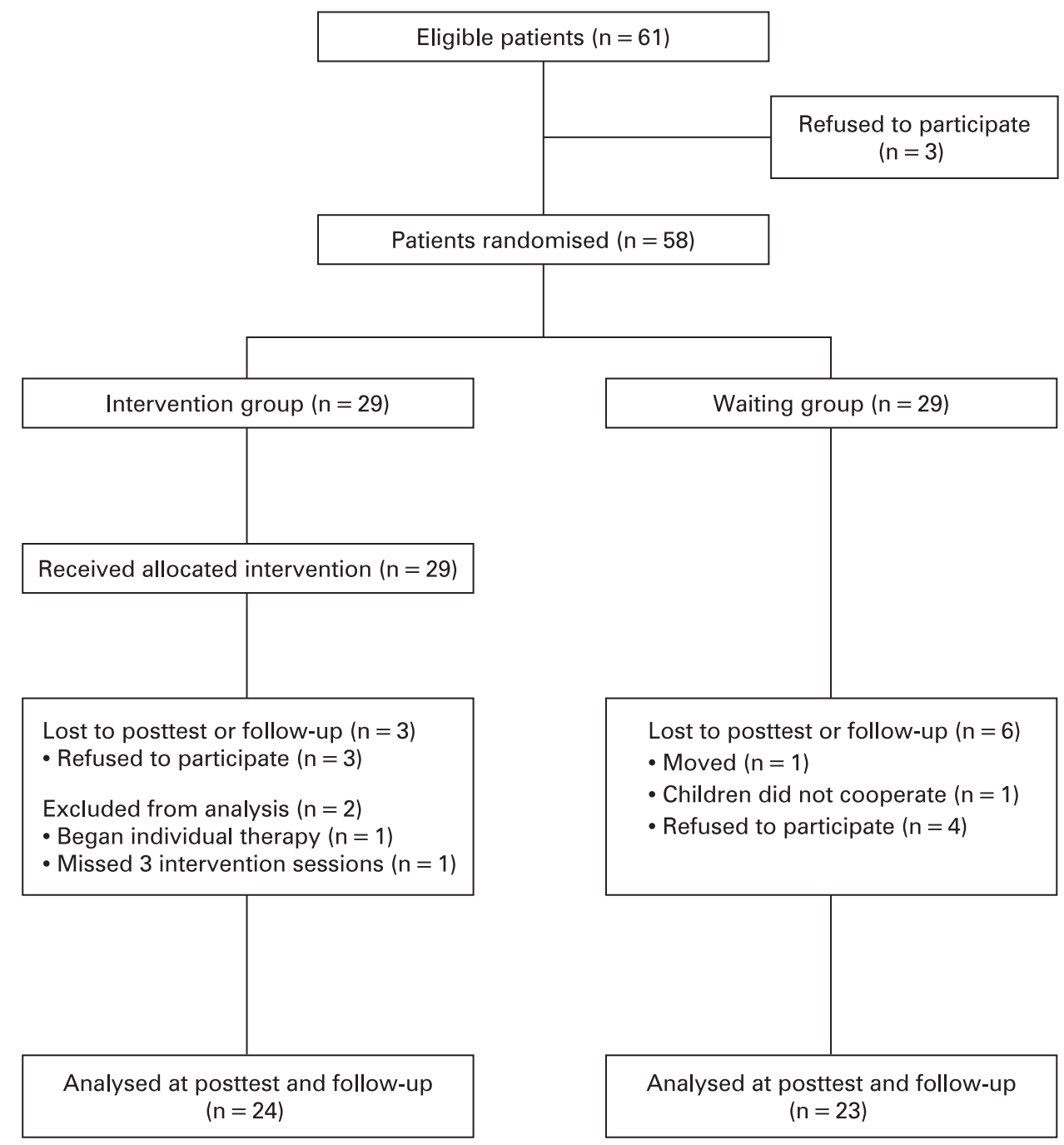

Figure 1 Flowchart of patient involvement in the study.

Different parent based group approaches are effective $e^{19-22}$ and well established in North America and the UK, but they do not seem to be cheaper or less time consuming than individual directed interventions. ${ }^{21}$ Evaluated parent based intervention programmes are not available in German speaking countries.

The purpose of this study was to examine the effectiveness of a short and highly structured parent based language intervention group programme for 2 -year-old children with SELD. The main hypothesis was that 2-year-old children with SELD whose mothers participate in the intervention, will show improved expressive language abilities 6 and 12 months after pretest in comparison to children with SELD in a waiting group. The results of both clinical groups were compared to the results of a matched reference language-normal sample. Confirmation of significant intervention effects might have substantial practical implications for providing support for children with SELD.

\section{METHOD}

\section{Study design}

The randomised controlled trial (RCT), completed in the Children's Hospital, University of Heidelberg, utilised a pretest-post-test control group design with follow-up 12 months after pretest.
Based on three frequently cited studies, a power calculation for single sided $t$ tests was used to determine the sample size. $^{192324}$ If $\alpha$ was set at 0.05 and $\beta$ was $0.80,14$ subjects per group were required. It was decided to aim for a sample size of 20 subjects per group.

Randomisation was carried out sequentially after pretest to achieve a balanced parallel group design stratified for gender and maternal school education because earlier studies found a correlation between maternal education and language development at the age of 3 and 4 years. ${ }^{11}$ Randomisation was carried out using opaque sealed envelopes. Post-test and follow-up diagnostics were carried out by different assessors who were blinded to previous results and allocation.

The study received ethical approval from the Ethics Committee of the University of Heidelberg.

\section{Participants}

Sixty one children with SELD were selected from a sample of children with language delay, identified in general paediatric practices during free routine developmental check-ups at 2124 months of age from October 2003 to February 2006. ${ }^{3}$ Inclusion criteria were singletons born at term without pre-, peri- or postnatal complications and a German speaking family background. Exclusion criteria were chronic hearing deficits, 
Table 1 Demographic and clinical data of children in the intervention group, the waiting group and a reference language-normal group

\begin{tabular}{|c|c|c|c|c|}
\hline & $\begin{array}{l}\text { Intervention } \\
\text { group, } n=24 \\
\text { (13 males/ } \\
11 \text { females) }\end{array}$ & $\begin{array}{l}\text { Waiting group, } \\
n=23 \\
\text { (11 males/ } \\
12 \text { females) }\end{array}$ & $\begin{array}{l}\text { Fisher's } \\
\text { exact } \\
\text { test }{ }^{*}\end{array}$ & $\begin{array}{l}\text { LN group, } \\
n=36 \\
\text { (20 males/ } \\
16 \text { females) }\end{array}$ \\
\hline Birth order, \% & & & $0.22 \mathrm{NS}$ & \\
\hline First born & 20.8 & 43.5 & & 41.7 \\
\hline Second born & 62.5 & 39.1 & & 50.0 \\
\hline Third or fourth born & 16.7 & 17.4 & & 8.3 \\
\hline Family history of SLD (1st degree), \% & 50.0 & 43.5 & $0.77 \mathrm{NS}$ & 2.8 \\
\hline Age of mothers at birth, mean (SD), years:months & $32: 1(3: 8)$ & $33: 7(4: 3)$ & & $31: 7(4: 4)$ \\
\hline Maternal school education (years in school), \% & & & $0.58 \mathrm{NS}$ & \\
\hline No/low graduation (8-9) & 12.5 & 8.7 & & 11.1 \\
\hline Middle school graduation (10) & 37.5 & 56.5 & & 47.2 \\
\hline High school graduation (13) & 50.0 & 34.8 & & 41.7 \\
\hline Maternal work situation, \% & & & $0.57 \mathrm{NS}$ & \\
\hline Full time employment & 8 & 4 & & 3 \\
\hline Part time employment & 38 & 52 & & 44 \\
\hline House wife & 54 & 44 & & 53 \\
\hline
\end{tabular}

${ }^{*}$ Comparison of intervention and waiting group.

LN, language-normal; NS, not significant; SLD, speech and language disorder.

persistent middle ear effusion accompanied by a significant hearing loss of $>20 \mathrm{~dB}$, visual impairments, genetic syndromes, pervasive developmental disorders or other diseases with a known influence on language development, deficits in receptive language and/or in non-verbal cognitive abilities, and previous language intervention. The children were between 24 and 27 months of age at entry into the study (mean age 24.7 months, SD 0.9). None of these children had reached the critical cut-off of 50 words in their expressive vocabulary as measured by the parent-report screening questionnaire ELFRA-2. ${ }^{25}$

Nine families dropped out before follow-up. Two families from the intervention group were excluded from analysis, resulting in a final sample of 47 children with SELD (fig 1).

To obtain a reference language-normal group, an advertisement was placed in a local newspaper. A total of 36 children (mean age 24.6 months, SD 0.8) were matched as closely as possible with respect to age, sex, birth order and maternal school education.

Demographic and clinical data are presented in table 1.

\section{Measures}

During the routine paediatric check-up, parents completed the ELFRA-2 (the German version of the MacArthur Communicative Development Inventories), ${ }^{26}$ a reliable and easy to use parent-report screening questionnaire for the early identification of children with language delay. ${ }^{27}$

At pretest, children were tested with the widely used developmental language test for 2-year-old children (SETK-2), a standardised and norm-referenced instrument to examine the language status of German speaking children. ${ }^{28}$ Two subtests measure language comprehension and two subtests measure word production (naming objects/pictures) and sentence production (explaining pictures). Cognitive abilities were assessed with the Mental Scale of the Bayley Scales of Infant Development, 2nd edition, Netherlands version (BSID-II-NL) which offers norms for a general mental developmental index (MDI) and for a non-verbal MDI. ${ }^{29}$ Only children with normal non-verbal cognitive abilities (non-verbal MDI>85) were included. Audiometric testing was carried out for all children to exclude those with persistent middle ear effusion accompanied by a significant hearing loss of $>20 \mathrm{~dB}$. A neurological examination was performed by a paediatric neurologist to exclude children with neurological diseases.

At post-test, expressive language was standardised assessed with the two production subtests of the SETK-2; in addition, parents completed the ELFRA-2 questionnaire.

At follow-up, expressive language was tested with the two production subtests of the SETK 3-5, a standardised and normreferenced instrument to examine the language status of German speaking preschool children (reliability coefficients 0.62-0.86). ${ }^{30}$ Language production was measured with the subtest Encoding Semantic Information (ESI) in the same manner as with the two production subtests of the SETK-2. The other subtest measures the ability of plural forming (PF). Parents completed the ELFRA-2 questionnaire research version, which includes six additional syntactic items for better differentiation of 3 -year-old children. ${ }^{25}$

Results within normal limits ( $t$ score $\geqslant 40$ ) in both production subtests of the SETK 3-5 indicated the child had caught up. Specific language impairment was defined by a t score of more than $1.5 \mathrm{SD}$ below the mean $(\leqslant 35)$ in at least one production subtest of the SETK 3-5.

All diagnostic sessions were recorded on videotape.

\section{Intervention programme}

The intervention used was the Heidelberg Parent-based Language Intervention (HPLI), ${ }^{31}{ }^{32}$ a highly structured and interactive programme developed for use with a group of 5-10 parents. The 3 -month programme consisted of seven $2 \mathrm{~h}$ and one 3 h session 6 months later.

The HPLI is based on an interactive model of language intervention, which presumes that optimised parental input will provide better language learning opportunities for children. ${ }^{33}$ Parents are introduced to child oriented, interaction promoting and language modelling techniques. ${ }^{34}$ Sharing picture books is one of the main topics of the programme, since picture book sharing is an ideal time to initiate communication as well as being a prototypical situation for learning words at the age of $2 .^{24}$ 
Table 2 Pretest comparisons on language and cognitive abilities

\begin{tabular}{|c|c|c|c|c|c|c|c|c|c|c|c|}
\hline Pretest & $\begin{array}{l}\begin{array}{l}\text { Inter- } \\
\text { vention } \\
\text { group, } \\
\mathrm{n}=24\end{array} \\
\text { Mean (SD) }\end{array}$ & $\begin{array}{l}\begin{array}{l}\text { Waiting } \\
\text { group, } \\
\mathrm{n}=23\end{array} \\
\text { Mean (SD) }\end{array}$ & $\begin{array}{l}\text { LN group, } \\
n=36 \\
\text { Mean (SD) }\end{array}$ & \multicolumn{2}{|l|}{ ANOVA } & \multicolumn{2}{|c|}{$\begin{array}{l}\text { Comparison of } \\
\text { intervention and } \\
\text { waiting groups }\end{array}$} & \multicolumn{2}{|c|}{$\begin{array}{l}\text { Comparison of } \\
\text { intervention and } \\
\text { LN groups }\end{array}$} & \multicolumn{2}{|c|}{$\begin{array}{l}\text { Comparison of } \\
\text { waiting and LN } \\
\text { groups }\end{array}$} \\
\hline \multicolumn{12}{|c|}{ Assessment of language abilities } \\
\hline \multicolumn{12}{|c|}{ ELFRA-2 (parent report)* } \\
\hline Age in months & $23.9(1.0)$ & $24.5(0.8)$ & $24.2(0.7)$ & $F(2,80)=2.9$ & 0.062 & -2.2 & 0.034 & -1.5 & 0.155 & 1.1 & 0.263 \\
\hline Morphology & $0(0)$ & $0(0)$ & $8.0(3.8)$ & $F(2,80)=104.5$ & $<0.001$ & - & - & -12.7 & $<0.001$ & -12.7 & $<0.001$ \\
\hline \multicolumn{12}{|l|}{ SETK- $2 \uparrow$} \\
\hline Age in months & $24.5(0.9)$ & $24.9(0.9)$ & $24.6(0.8)$ & $F(2,80)=1.3$ & 0.277 & -1.5 & 0.130 & -0.9 & 0.395 & 0.9 & 0.369 \\
\hline \multicolumn{12}{|l|}{ Comprehension } \\
\hline Words & $52.2(8.8)$ & $50.9(5.6)$ & $56.3(7.2)$ & $F(2,80)=4.6$ & 0.015 & 0.6 & 0.561 & -1.9 & 0.064 & -3.2 & 0.002 \\
\hline Sentences & $51.0(7.9)$ & $49.0(7.5)$ & $58.4(10.4)$ & $F(2,80)=9.2$ & $<0.001$ & 0.9 & 0.390 & -3.1 & 0.003 & -4.0 & $<0.001$ \\
\hline \multicolumn{12}{|c|}{ BSID-II-NL§ } \\
\hline MDI & $96.2(6.9)$ & $95.3(8.1)$ & $114.3(10.5)$ & $F(2,80)=43.7$ & $<0.001$ & 0.4 & 0.714 & -8.0 & $<0.001$ & -7.8 & $<0.001$ \\
\hline Non-verbal MDI & $115.2(10.1)$ & $109.6(12.6)$ & $116.5(10.5)$ & $F(2,80)=2.9$ & 0.063 & 1.7 & 0.101 & -0.5 & 0.64 & -2.2 & 0.034 \\
\hline
\end{tabular}

"Raw score; †SETK-2, for description of this language test see Buschmann et $a^{\beta}$; $\nmid$ t score normative means are 50 (SD 10); §standard score normative means are 100 (SD 15); $\lceil$ ANOVA over all three groups; **two sided $t$ test adjusted for multiple testing using Bonferroni corrections.

BSID-II-NL, Bayley Scales of Infant Development, 2nd edn, Netherlands version; ELFRA-2, [Parent report screening questionnaire for early identification of children at risk]; LN, language-normal; MDI, mental developmental index; SETK-2, [Developmental language test for 2-year-old children].

The intervention started when the children were about 25 months old. To achieve comparability only mothers took part; about seven mothers took part in each group. All sessions took place at the Children's Hospital, University of Heidelberg and were conducted by the first author who had developed the HPLI.

\section{Statistical analysis}

Statistical analysis was performed using SAS (v 8.01). Frequency differences between groups were tested for using the $\chi^{2}$ or Fisher's exact test. Pretest comparisons were made using analysis of variance (ANOVA) followed by two sided t tests. A series of ANOVAs, single sided t tests, calculation of effect sizes (Cohen's d) ${ }^{35}$ and repeated measurements MANOVAs (using the non-verbal MDI as a covariate) were administered to test for treatment effects. All hypotheses were directional, so the one tailed probability level was set at 0.05 .

\section{RESULTS}

The results are presented in three sections below: (1) pretest, (2) post-test and (3) follow-up comparisons of the intervention group, waiting group and reference language-normal group.

\section{Pretest comparisons}

The three groups differ significantly on all language scores and on general mental abilities (ANOVA, table 2). The intervention and waiting groups did not differ significantly on any of the demographic data (table 1) or on any language score (table 2). Language comprehension was age appropriate in both clinical groups. The language-normal group differ significantly from the intervention and waiting groups on all language scores (table 2) and on the variable family history of speech and language disorder (SLD) $\left(\chi^{2}\right.$ test, $\left.\mathrm{p}<0.001\right)$.

\section{Post-test comparisons}

At post-test all three groups showed an improvement in parent reported language scores. The language-normal group scored significantly higher compared with the clinical groups on all language scores (table 3). Children in the intervention group demonstrated greater gains than children in the waiting group in parent reported vocabulary, morphology, syntax as well as in both production subtests of the SETK-2, with medium to very large effect sizes (table 3 ). Regarding mean t scores, both clinical groups showed improvement in the subtest word production. However, in the subtest sentence production, only the intervention group improved their mean t score (tables 2 and 3 ).

\section{Follow-up comparisons}

\section{Between groups}

Twelve months after pretesting all three groups showed a further increase in parent reported language scores. The language-normal group scored significantly higher compared with the clinical groups on all language scores. Significant group differences between the intervention and waiting groups were found for parent reported vocabulary and morphology as well as for the subtest Encoding Semantic Information (ESI) (table 3).

Figure 2 shows the means and the 95\% confidence intervals for language production test scores at pretest, post-test and follow-up for the intervention and waiting groups. The two production subtests of the SETK-2 were combined at pretest and post-test. At follow-up the subtest Encoding Semantic Information (ESI) was used for analysis. A repeated measurements MANOVA (with the non-verbal MDI as covariate) showed a significant main effect for group $(F(1,97)=8.23$, $\mathrm{p}=0.006)$ as well as a significant interaction between group and tests $(F(2,39)=3.80, p=0.026)$, but not a significant test effect $(F(2,39)=2.26, p=0.11)$ for language production at follow-up. For the subtest Plural Forming (PF), a group effect 


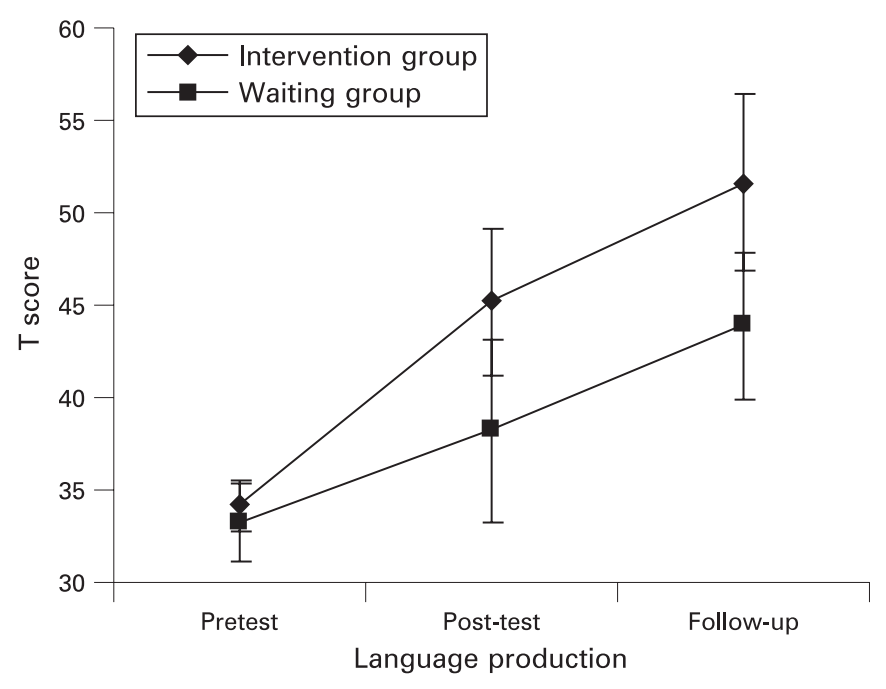

Figure 2 T scores (mean value, 95\% confidence interval) for language production at pretest, post-test and follow-up for the intervention and waiting groups.

$(\mathrm{F}(1,92)=2.84, \mathrm{p}=0.1)$ and an interaction between group and tests $(F(2,33)=2.65, p=0.08)$ were found, but they failed the 0.05 significance level. There was no test effect $(F(2,33)=0.31$, $p=0.74$ ) (adjusted by Greenhouse-Geisser).

\section{Across time}

For language production a very significant time effect between pretest, post-test and follow-up $(\mathrm{F}(1,29)=51.16, \mathrm{p}<0.001)$ and an interaction between time and group $(F(1,29)=7.59$, $p=0.008$ ) was revealed.

\section{Number of individuals who "caught up"}

At follow-up, 18 children (75\%) in the intervention group, 10 children $(43.5 \%)$ in the waiting group and all children in the language-normal group showed results within the normal limits ( $t$ score $\geqslant 40$ ) for expressive language. In the intervention group, two children $(8.3 \%)$ fulfilled the diagnosis of specific language impairment ( $t$ score $\leqslant 35$ ) versus six children $(26.1 \%$ ) in the waiting group and none in the language-normal group. There was no significant difference regarding gender (1) or maternal school education (2) between intervention group children who "caught up" in comparison to those who showed continuing impaired expressive language ((1) $p=0.17$, (2) $p=0.29$, Fisher's exact test) or between children in the waiting group who caught up compared to children with persistent impaired expressive language ((1) $p=0.21 ;(2) p=0.67)$.

\section{Cost effectiveness}

The HPLI costs $£ 270$ per child. In Germany the cost of one individual directed therapy session is £28. Because individual therapy for children with specific language impairment takes an average of 43 sessions, ${ }^{7}$ the labour costs amount to $£ 1204$ per child. As six children in the intervention group needed individual directed therapy, the labour costs amounted to $£ 13704$ for the whole intervention group, including the cost of the HPLI and the expected cost for additional individual directed therapy for the six children. In the waiting group 13 children needed individual therapy, so the expected cost was £15 652 .

\section{DISCUSSION}

In this RCT we examined the effectiveness of the HPLI in a group of 2-year-old children with SELD. The results support previous evidence that early parent based language intervention is effective in the short term. ${ }^{19}$ During the 6- and 12-month intervals, children in the intervention group made developmental gains in vocabulary and grammatical abilities over and above the maturational changes seen in the waiting group. However, the most important result was that the percentage of children who showed standardised scores within normal limits in expressive language and therefore had caught up with their peers at the age of 3 , was $75 \%$ in the intervention group in contrast to $44 \%$ in the waiting group. Thus, the percentage of children who needed to start additional individual directed language therapy was significantly lower in the intervention group compared to the waiting group. These differences are suggested to be the result of participating in a highly structured and short parent based language intervention. These findings support previous evidence that the interactive style of mothers may be optimised to provide a superior language learning environment and accelerate the language development of latetalking toddlers. ${ }^{19}$

Since the subjects showed only expressive language delay, the results cannot be generalised to children with additional deficits in receptive language or to children with concurrent cognitive deficits. In addition, despite impressive improvement due to our intervention, the expressive language abilities of the intervention group remained significantly lower compared to the language-normal group.

The importance of the HPLI as an effective prevention programme is underscored by the fact that there is only little evidence for the effectiveness of individual therapy implemented in preschool children. ${ }^{36}$ Compared to the established Hanen Parent Programme (HPP), ${ }^{37}$ the HPLI offers a more structured approach, takes a shorter time and is less expensive and time consuming. ${ }^{21}$ It is carried out without home visits by a single HPLI-trained therapist.

The results of our study have important clinical implications for providing support for children with SELD. Currently, parent report screening questionnaires such as the MacArthur Communicative Development Inventories are seldom used in German speaking countries to identify children with language delay, even though they can be easily used in general paediatric practice. $^{27}$ One reason for their low acceptance could be that currently there are no guidelines on how to most appropriately provide support for children with language delay. While the wait and see approach is widely used, it cannot be recommended on the basis of our results for the following reasons. First, the heterogeneity of children with language delay makes further diagnostic work-up necessary. ${ }^{3}$ Second, the persistence of language impairments in a substantial number of children together with related educational, social-emotional and behavioural problems clearly indicates the need for early language intervention that helps children develop normal linguistic functioning as quickly as possible. One possible approach is a parent based intervention with the advantage that parents are perceived to be competent partners in the facilitation of language development. According to our results, the HPLI also seems to be successful in families with low socio-economic status.

The results of this RCT show that the HPLI is an effective and cost saving approach in providing support for children with SELD. Further follow-up investigations are necessary to evaluate the long term effectiveness of the HPLI. 


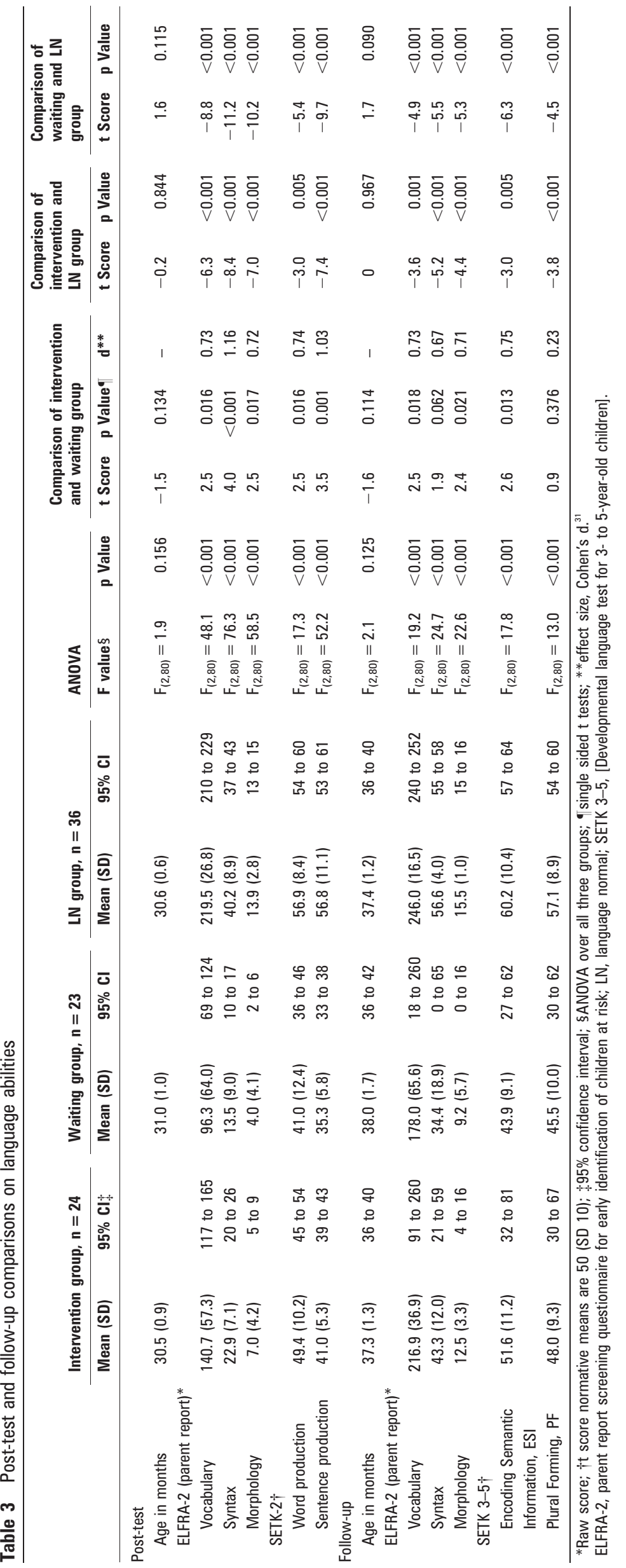


Acknowledgements: We thank Professor Hannelore Grimm and Professor Ute Ritterfeld for their help in initiating this project. We are grateful to Tamara Wirt, Meike Neubauer, Carolin Sallinger, Iris Heggen, Heike Blaschtikowitz, Annette Koch-Graus and Dieter Schumacher for their support in the diagnostic work-up.

Funding: This study was funded by the Leopold Klinge Foundation, the C.D. Foundation, the Zonta Club Heidelberg and the Günter-Reimann-Dubbers Foundation. These foundations were not involved in the study design, the collection, analysis and interpretation of the data, in the writing of the manuscript or in the decision to submit.

Competing interests: None.

Ethics approval: This study was approved by the Ethics Committee of the University of Heidelberg.

We declare that we participated in the study entitled "Parent based language intervention for 2-year-old children with specific expressive language delay: a randomised controlled trial", and that we have seen and approved the final version. We shared in designing and executing the study, analysing the results and writing the manuscript. It has been neither published nor submitted elsewhere.

\section{REFERENCES}

1. Horwitz SM, Irwin JR, Briggs-Gowan M, et al. Language delay in a community cohort of young children. J Am Acad Child Adolesc Psychiatry 2003:42:932-40.

2. Reilly S, Wake M, Bavin EL, et al. Predicting language at 2 years of age: a prospective community study. Pediatrics 2007;120:1441-9.

3. Buschmann A, Jooss B, Rupp A, et al. Children with developmental language delay at 24 months of age: results of a diagnostic work-up. Dev Med Child Neurol 2008:50:223-9.

4. Paul R. Predicting outcomes of early expressive language delay: ethical implications. In: Bishop DVM, Leonard LB, eds. Speech and language impairments in children: causes, characteristics, intervention and outcome. East Sussex, UK: Psychology Press, 2000:195-209

5. Deutsche Gesellschaft für Kinder- und Jugendpsychiatrie und

Psychotherapie (Hrsg). Leitlinien zur Diagnostik und Therapie von psychischen Störungen im Säuglings-, Kindes- und Jugendalter. 3. überarbeitete Auflage. Cologne: Deutscher Ärzte Verlag, 2007:197-206.

6. Whitehurst GJ, Fischel JE. Early developmental language delay: what, if anything, should the clinician do about it? J Child Psychol Psychiatry 1994;35:613-48.

7. De Langen-Müller U, Hielscher-Fastabend M. Retro quant - a retrospective documentation of quantitative data on speech and language therapy with children in Germany (In German). Sprachheilarbeit 2007;2:48-62.

8. Paul R. Patterns of development in late talkers: preschool years. J Child Commun Disord 1993;15:7-14.

9. Rescorla L, Mirak J, Singh L. Vocabulary growth in late talkers: lexical development from 2;0 to 3;0. J Child Lang 2000;27:293-311.

10. Rescorla L, Dahlsgaard K, Roberts J. Late-talking toddlers: MLU and IPSyn outcomes at 3;0 and 4;0. J Child Lang 2000;27:643-64.

11. Dale PS, Price TS, Bishop DVM, et al. Outcomes of early language delay: I. Predicting persistent and transient language difficulties at 3 and 4 years. J Speech Lang Hear Res 2003:46:544-60.

12. Roulstone S, Peters TJ, Glogowska M, et al. A 12-month follow-up of preschool children investigating the natural history of speech and language delay. Child Care Health Dev 2003;29:245-55.

13. Johnson CJ, Beitchman JH, Young A, et al. Fourteen-year follow-up of children with and without speech/language impairments: speech/language stability and outcomes. J Speech Lang Hear Res 1999;42:744-60.
14. Shevell MI, Majnemer A, Webster RI, et al. Outcomes at school age of preschool children with developmental language impairment. Pediatr Neurol 2005;32:264-9.

15. Snowling MJ, Bishop DVM, Stothard SE, et al. Psychosocial outcomes at 15 years of children with a preschool history of speech-language impairment. J Child Psychol Psychiatry 2006;47:759-65.

16. Olswang $\mathbf{L}$, Rodriguez $R$, Timler $G$. Recommending intervention for toddlers with specific language learning difficulties: we may not have all answers, but we know a lot. Am J Speech Lang Pathol 1998; 7:23-32.

17. Robertson SB, Weismer E. Effects of treatment and social skills in toddlers with delayed language development. J Speech Lang Hear Res 1999:42:1234-48.

18. Lederer SH. Efficacy of parent-child language group intervention for late-talking toddlers. Infant-Toddler Intervention 2001;11:223-35.

19. Girolametto LE, Pearce PS, Weitzman E. Interactive focused stimulation for toddlers with expressive vocabulary delays. J Speech Hear Res 1996;39:1274-84.

20. Girolametto LE, Pearce PS, Weitzman E. Effects of lexical intervention on the phonology of late talkers. J Speech Lang Hear Res 1997; 40:338-48.

21. Baxendale J, Hesketh A. Comparison of the effectiveness of the Hanen Parent Programme and traditional clinic therapy. Int J Lang Commun Disord 2003;38:397-415.

22. Gibbard D, Coglan L, MacDonald J. Cost-effectiveness analysis of current practice and parent intervention for children under 3 years presenting with expressive language delay. Int J Lang Commun Disord 2004;39:229-44.

23. Ward $\mathbf{S}$. An investigation into the effectiveness of an early intervention method for delayed language development in young children. Int J Lang Commun Disord 1999:34:243-64.

24. Whitehurst GJ, Falco FL, Lonigan CJ, et al. Accelerating language development through picture book reading. Dev Psychol 1988;24:552-9.

25. Grimm H, Doil H. Parent report screening questionnaire for early identification of children at risk, ELFRA (In German). Göttingen: Hogrefe, 2000.

26. Fenson L, Dale PS, Reznick JS, et al. Guide and technical manual for the MacArthur Communicative Development Inventories. San Diego: Singular Press, 1993.

27. Sachse S, Von Suchodoletz W. Early identification of language delay by direct language assessment or parent report. J Dev Behav Pediatr 2008:29:34-41.

28. Grimm H. Developmental language test for 2-year-old children SETK-2 (In German) Göttingen: Hogrefe, 2000.

29. Van der Meulen BF, Ruiter SAJ, Spelberg HCL, et al. Bayley Scales of Infant Development-II. Nederlandse Versie (BSID-II-NL) (in Dutch). Lisse: SwetsTest, 2002.

30. Grimm H. Developmental language test for 3-to-5-year-old children, SETK 3-5 (In German). Göttingen: Hogrefe, 2001.

31. Buschmann A. Handbook of Heidelberg Parent-based Language Intervention (In German). Munich: Elsevier Urban \& Fischer bei Elsevier, 2008.

32. Buschmann A, Jooss B. Early language intervention in late-talking toddlers: "Heidelberg Parent-based Language Intervention HPLI" (In German). Forum Logopädie 2007:5:6-11.

33. Hoff-Ginsberg E. Function and structure in maternal speech: their relation to the child's development of syntax. Dev Psychol 1986;22:155-63.

34. Tannok R, Girolametto L. Reassessing parent-focused language intervention programmes. In: Warren S, Reichle J, eds. Causes and effects in communication and language intervention. Baltimore: Brookes, 1992:49-80.

35. Cohen J. Statistical power analysis for the behavioral sciences. 2nd edn. Hillsdale, NJ: Erlbaum, 1988.

36. Glogowska M, Roulstone S, Enderby P, et al. Randomised controlled trial of community based speech and language therapy in preschool children. BMJ 2000;14:923-6.

37. Girolametto LE, Greenberg J, Manolsen A. Developing dialogue skills: the Hanen Early Language Parent Program. Semin Speech Lang 1986;7:367-82. 